

\title{
La institución del Conjuez en Colombia: Una mirada desde la jurisdicción contencioso administrativa*
}

\section{Nataly Vargas Ossa**}

\section{Resumen}

Se propone hacer un análisis de la institución del Conjuez en Colombia, observando su dinámica, particularmente en la jurisdicción contencioso administrativa. A partir de una revisión documental de la normatividad y la doctrina que se ha referido al tema, develar la discusión acerca de su naturaleza jurídica y su implementación en la jurisdicción contencioso administrativa, donde se observan dificultades en el desarrollo de la figura que pueden comprometer la imparcialidad, la independencia judicial y el desempeño del Conjuez en la tarea de administrar justicia.

Palabras clave: conjueces; administración de justicia; independencia judicial; imparcialidad judicial.

\section{The figure of Conjuez (Judge Pro Tempore) in Colombia: A revision from the contentious administrative jurisdiction}

\begin{abstract} dynamics, particularly in the contentious administrative jurisdiction. From a literature review of the regulations the development of the figure which may compromise impartiality, judicial independence and the performance of the Conjuez in the task of administering justice.

Keywords: conjueces (Judges Pro Tempore); Administration of Justice; judicial independence; judicial impartiality.

\section{A instituição de Conjuiz na República da Colômbia: uma olhada da jurisdição contenciosa administrativa}

This article makes an analysis of the figure of Conjueces (Judges Pro Tempore) in Colombia by observing their and doctrine that has been organized about the subject, we brought the discussion to the table about their legal nature and their implementation in the contentious administrative jurisdiction. Some difficulties are observed in

\section{Resumo}

Propõe-se fazer uma análise da instituição do Conjuiz nas varas da Colômbia, enxergando sua dinâmica, principalmente na jurisdição contenciosa administrativa. Baseados numa revisão documental dos regulamentos ea doutrina que já se referiu ao assunto, revelando a discussão atinente a sua natureza jurídica e a sua implementação na jurisdição contenciosa administrativa, onde são enxergadas dificuldades no desenvolvimento da figura que possam implicar a imparcialidade, a independência judicial e o desempenho do Conjuiz na incumbência de administrar a justiça.

Palavras-chave: conjuiz; Administração da Justiça; independência judicial; imparcialidade judicial.

* Artículo de reflexión derivado de investigación. Este hace parte de los resultados del proyecto de investigación: "Conjueces y Administración de Justicia", formulado desde la línea de investigación en Derecho Procesal Administrativo de la Maestría en Derecho Administrativo de la Universidad Autónoma Latinoamericana, Colombia; la investigadora principal es Nataly Vargas Ossa. La propuesta fue financiada por la UNAULA en el marco de las convocatorias de investigación de la Vicerrectoría de Investigaciones de la UNAULA y el proyecto concluyó el año 2018.

** Docente investigadora de la Escuela de Posgrados de la UNAULA, Colombia. Magíster en Derecho administrativo del Colegio Mayor Nuestra Señora del Rosario, integrante del grupo de investigación en Derecho Administrativo de la Maestría en Derecho Administrativo de la UNAULA, Colombia. Correo electrónico: nataly.vargasos@unaula.edu.co ORCID: orcid.org/0000-0003-2048-034X 


\section{La institución del Conjuez en Colombia: Una mirada desde la jurisdicción contencioso administrativa}

\section{Introducción}

Los Conjueces son abogados nombrados por la las Corporaciones Judiciales, para actuar como magistrados o consejeros de Estado, cuando se presenta un empate en una votación y cuando no es posible integrar el cuórum decisorio por la separación de uno o varios magistrados originada en un impedimento o en una recusación; el objetivo de su designación es propiciar las condiciones para que se dé una decisión de fondo en el trámite judicial y así procurar el derecho al acceso a la administración de justicia, de una parte, y de otra, que los operadores jurídicos que asumen el conocimiento del caso, gocen de la independencia e imparcialidad necesarias como expresiones propias del derecho al debido proceso La independencia e imparcialidad judicial del funcionario judicial, como parte del debido proceso encuentra una estrecha vinculación al régimen de impedimentos y recusaciones, puesto que proporcionan la salvaguarda de dicha garantía procesal.

La institución del Conjuez es una figura tratada tímidamente en los manuales de derecho procesal, no existe claridad acerca de su naturaleza jurídica y se percibe su intervención como excepcional en el sistema de administración de justicia; sin embargo, el papel que cumplen los Conjueces dentro de las distintas jurisdicciones es significativo ${ }^{1}$ y se ha incrementado de manera exponencial en la jurisdicción contencioso administrativa, como producto de los conflictos que en materia de derechos y prestaciones laborales que se han suscitado entre los magistrados, jueces, fiscales, procuradores y Rama Judicial, demandas que no han sido ajenas

1 Se pueden mencionar, sentencias que han generado aportes muy relevantes a discusiones relacionadas con el reconocimiento a la igualdad material, como la C-388 de 2016 acerca de la modificación del costo de la libreta militar, la C 071 de 2015 desarrolla un importante debate acerca de la posibilidad de adopción para parejas del mismo sexo, la C -077 de 2017 analiza juiciosamente la pertinencia creación de las zonas de interés y desarrollo rural Ziders y la C-258 de 2013 pone sobre la mesa los fundamentos que hacen insostenibles las mega pensiones, entre otras decisiones. 
a las dinámicas de un sistema de administración de justicia altamente solicitado, que sufre el represamiento continuo de procesos judiciales, generando mora judicial "por no contar con los recursos suficientes para atender su gestión, dentro de los términos establecidos en la norma procesal" (Londoño Jaramillo, 2008).

Como ya se expresó, se trata de asuntos de carácter laboral donde generalmente están comprometidos intereses de funcionarios judiciales, lo que conlleva a que estos mismos administradores de justicia, se declaren impedidos para conocer de los procesos por tener un interés directo o indirecto en el resultado del litigio, lo que consecuencialmente implica la necesidad de reconformar la sala de decisión (o nombrar un juez ad hoc, en caso de los jueces administrativos del circuito), haciendo uso de las listas de abogados externos que se postulan como Conjueces y jueces ad hoc ante dicha jurisdicción.

Así las cosas, se observa un importante número de procesos ${ }^{2}$ asignados para cada Conjuez y juez ad hoc, función que se cumple de manera precaria y desventajosa, ya sea porque los terceros que han sido nombrados no cuentan con los recursos propios de un despacho judicial de la categoría que representa, o por un posible desconocimiento del tema que ha sido llamado a dirimir, o por la escasez de tiempo que disponen para atender dentro de los términos judiciales el trámite procesal (pues su actividad profesional principal como empleado privado, litigante, docente, consultor, etc., se lo impide, ya que de eso es que vive); y, sumado a ello, el desconocimiento absoluto de su derecho a percibir una remuneración acorde con la labor desempeñada y a la dignidad del cargo (aclarando que se da la misma exigencia en el cumplimiento de los deberes y responsabilidades que cualquier administrador de justicia).

Bajo el panorama anterior, se propuso adelantar una investigación, que busca analizar la implementación de la institución jurídica del Conjuez en la jurisdicción contencioso administrativa (en adelante JCA), bajo la perspectiva al debido y el derecho acceso a la administración de justicia En ese orden de ideas, se propuso como objetivo central: Analizar la implementación de la institución jurídica del Conjuez, de cara al derecho al acceso a la administración de justicia (mora judicial) y al debido proceso (independencia e imparcialidad) desde su desarrollo en la Jurisdicción contencioso administrativa en Colombia. El presente escrito da a conocer el resultado de la revisión documental de la normatividad y la doctrina que se ha referido al tema, para develar la discusión acerca de su naturaleza jurídica y su nacimiento e implementación en la JCA, donde se observan dificultades en el

2 Por Ejemplo, en el Consejo de Estado, con corte al año 2017, según información remitida por la relatoría de la corporación, existen 692 procesos a cargo de 32 (sin contar la sección tercera, que reportó 18 Conjueces, pero ningún proceso activo). La relatoría del Tribunal Administrativo de Antioquia reporta 441 procesos activos a cargo de 54 Conjueces, la del Tribunal Administrativo de Cundinamarca 767, para 20 Conjueces, la del Tribunal Administrativo de Caldas 157 para 10 conjueces y la relatoría del Tribunal Administrativo de Boyacá 149 para 7 Conjueces. 
desarrollo de la figura, que pueden comprometer la imparcialidad y desempeño del Conjuez en la tarea de administrar justicia, así como algunos aspectos relativos a las estadísticas que se lograron recoger.

\section{Aproximación normativa de la institución del conjuez, en Colombia: caso de la jurisdicción contencioso administrativa}

\section{Antecedentes normativos}

La institución de los Conjueces en el ordenamiento jurídico colombiano ha estado presente a lo largo del nacimiento y desarrollo de las distintas jurisdicciones. Desde la Ley séptima de 1838 se indicó que estos acudirían a los trámites procesales, con el fin de completar los cuórum requeridos para las decisiones judiciales, cuando los magistrados se declararan impedidos y fueran recusados. En cuanto a los requisitos exigidos para ostentar la calidad de Conjuez, son idénticos a los requeridos para ser magistrado de la Corte Suprema de Justicia, miembro de Tribunal y de Juzgado (Ley 1 de 1834), así como los mismos impedimentos señalados en la Ley de 1842.

Fue el Código Judicial adoptado por la Ley 57 de 1887, dónde se recogieron de manera más precisa las normas aplicables a los Conjueces y, así mismo, se ocupó de la forma como se elaboraban las listas, prohibió que los empleados del ministerio público, de la Rama Ejecutiva, judicial o legislativa, fueran nombrados Conjueces, describió las funciones que cumplirían, los impedimentos, derechos, deberes, y estableció la aceptación forzosa del cargo. Por su parte, la expedición de la Ley 72 de 1890 reguló su remuneración, la cual se estableció a través del pago de honorarios.

Con el surgimiento de las funciones jurisdiccionales atribuidas a la Jurisdicción Contencioso-Administrativa, con la Ley 130 de 1913 (como consecuencia de lo dispuesto en el acto legislativo 3 de 1910, suprimido con el acto legislativo 10 de 1905), se identifica claramente la existencia de la figura del Conjuez:

Artículo 15. El Tribunal Supremo debe formar anualmente una lista de seis Conjueces, designados a llenar las faltas de los Magistrados en los casos de impedimento o de recusación, y a intervenir en las decisiones, en los casos de empate.

Son comunes a estos Conjueces las disposiciones del Código Judicial relativas a los de la Corte Suprema de Justicia y tienen aquellos la misma remuneración señalada a éstos. (Congreso de la República de Colombia, 1910) 
Por su parte, la Ley 81 del 18 de noviembre de $1910^{3}$, por remisión expresa de la Ley 130 de 1913, precisó la forma cómo se conformarían las listas de Conjueces, y su papel como terceros:

Artículo 15. En lo sucesivo habrá dos listas de Conjueces: una de doce para la Sala de Casación, y otra de seis, para la Sala de Negocios Generales. Cada año, en los quince primeros días del mes de diciembre, formará la respectiva Sala su lista de Conjueces para el siguiente año. Las mismas Salas llenaran las vacantes que vayan ocurriendo en sus respectivas listas, por faltas absolutas de los Conjueces o por haber dejado éstos de ser vecinos de la capital. La reunión de las dos listas formará la de Conjueces de la Corte Plena (sic).

Artículo 20. En todo caso de empate será dirimido éste por uno de los Conjueces de la respectiva Sala, sorteado en la forma legal. (Congreso de la República de Colombia, 1910)

La Ley 167 de 1941, reprodujo íntegramente lo dispuesto por la Ley 1304; dicha norma contempló de manera similar el tema en los artículos 37, 18 y 11, y, en este último, se atribuye al Consejo de Estado la competencia para la resolución de los impedimentos y recusaciones de los mismos Conjueces y su exclusión de la lista, pero en general, no dista de lo contemplado en el primer código contencioso.

Pasados más de cuarenta años, con la entrada en vigencia del Decreto 01 de 1984, los artículos 99, 99A, 102, 160A y 160B, recogieron el desarrollo legislativo de la de la figura del Conjuez, donde nuevamente se reiteran los requisitos específicos para acceder al cargo, las responsabilidades a que están sometidos, la forma de su elección y exclusión de la lista, así como los casos en que se deben llamar a cumplir sus funciones:

Artículo 99. Para ser Conjuez se requerirán las mismas calidades que para ser Consejero de Estado, sin que obste el haber llegado a la edad de retiro forzoso.

Los Conjueces llenarán las faltas de los consejeros por impedimentos o recusación, dirimirán los empates que se presenten en las Salas Plena de lo Contencioso Administrativo y de Consulta y Servicio Civil

3 Beatriz Eugenia Salamanca Charria, explica en su texto Anotaciones sobre la Historia del Derecho Procesal y la Administración de Justicia, antes de la Constitución de 1886, cada Estado soberano tenía su propio Código Judicial y el de la Unión fue prácticamente transcrito del Código Judicial del Estado de Cundinamarca. Este había sido tomado del Código de Procedimiento Civil chileno, elaborado por Andrés Bello, entre 1840 y 1852, que a su vez era bastante similar a la Ley de Enjuiciamiento Civil de España de 1855. Tras la Constitución de 1886, continuó vigente a través de la Ley 57 de 1887, pero con la Ley 103 de 1923, perdió definitivamente su vigencia.

4 Según el autor Gustavo Humberto Rodríguez (1983), en su texto la jurisdicción y el procedimiento contencioso administrativo, historia desarrollo y perspectivas, le atribuye a la ley 167 de 1941, la creación de la institución de los Conjueces, afirmación de la cual discrepo, pues ya existía bajo la regulación de la ley 130 de 1913. 
e intervendrán en las mismas, para completar la mayoría decisoria, cuando ésta no se hubiera logrado. (Presidente de la República 1984)

Bajo esta nueva regulación normativa, es posible identificar varias tipologías de Conjueces: i) los Conjueces externos, integrados por aquellos abogados que cumpliendo requisitos para ser magistrados de Tribunal o Consejeros de Estado, se postulan y resultan seleccionados por la Sala Plena de las distintas corporaciones para hacer parte de una lista que tiene vigencia de 1 año y ii) Los Conjueces que son jueces, integrado por aquellos funcionarios judiciales, que ya siendo magistrados o consejeros de Estado, a través de una simple comunicación pueden ser llamados, en calidad de Conjueces a conformar una sala de decisión para completar un cuórum o desempatar una votación. Por su parte, el artículo 15.2 del Decreto-Ley 1265 de 1970 estableció que: "si se trata de tribunales superiores, se llamará por turno a otro de los magistrados de la sala respectiva, para que integren la decisión, y sólo en defecto de ellos se sortearán los conjueces necesarios" (Ministerio de Justicia, 1970, Decreto-Ley 1265). iiii) Los Jueces ad hoc, los cuales no son mencionados en la norma procesal civil ni contencioso administrativa, pero que a partir de la creación de los juzgados administrativos con la Ley 446 de 1998 (artículo 42), y ante el alto número de procesos donde se han declarado impedidos la totalidad de los jueces administrativos, hace que surja la necesidad de crear una lista de jueces que han denominado jueces ad hoc, destinada a satisfacer el servicio de público de administración de justicia, en casos donde todos los jueces administrativos del distrito judicial resulten impedidos para conocer de algún proceso judicial. Dichos jueces, igual que los Conjueces, son particulares que transitoriamente quedan revestidos para administrar justicia y pese a no ser una figura que haya sido creada directamente por el legislador, como sí lo hizo con los Conjueces, igualmente deberían estar sometidos al mismo régimen jurídico.

El Decreto 01 de 1984 en el artículo 99 hizo una expresa remisión al Decreto 1265 de 1970, norma que en los artículos 11,15, 16, 17 y 18, precisó la forma cómo se seleccionan a los conjueces ponentes. Las particularidades que debe respetar el sorteo y la publicidad que debe existir en la conformación de las listas y selección de los conjueces. Así la norma hace énfasis especial en el deber del Conjuez de cumplir a cabalidad la totalidad de los trámites procesales de la instancia, en el negocio asignado, a pesar de que haya renunciado a la lista; no obstante, pueden ser relevados o desplazados del cargo si se modifica el personal de la Sala, y los nuevos magistrado no están incursos en impedimentos. Esta medida fue tomada en 2019 por la Dirección Ejecutiva de la Administración Judicial, en los casos de los jueces ad hoc con la expedición del Acuerdo PCSJA19-11331.

Finalmente, la norma también se refirió al deber de remuneración de la actividad, asimilándolo a una prestación de servicios, y las directrices están en cabeza del ejecutivo mediante decreto reglamentario (Decreto 2204 de 1969 - Decreto 2266 de 1969). 
Ineficacia de la norma que regula la remuneración del trabajo de Conjuez

la remuneración por honorarios de los Conjueces ha sido regulada únicamente por el Decreto reglamentario 2266 de 1969, ni las normas estatutarias, ni las normas procesales expedidas con posterioridad se han ocupado del tema. Se trata de una norma de casi veinte años, de la cual no solo se conserva su vigencia, sino también la potestad del ejecutivo para expedir el reglamento respectivo, sobre el particular, la Sala de Consulta y Servicio Civil conceptuó que:

(...) la competencia establecida en el Decreto Extraordinario 2204 de 1969 para que el Gobierno Nacional fije los honorarios de los Conjueces se encuentra vigente. Incluso, aún si se considerara que dicho decreto está derogado, la competencia del Gobierno Nacional viene dada, necesariamente, de lo dispuesto en la Ley $4^{\mathrm{a}}$ de 1992, que le asigna al Gobierno Nacional la competencia general para dictar el régimen de remuneración de los servidores públicos de las distintas ramas del poder público, inclusive la judicial. (Sala de Consulta y Servicios Civil, 2016)

La Sala de Consulta, además de explicar que las normas que atribuyen competencia al Ejecutivo para regular la remuneración del Conjuez están vigentes, permite pensar que, bajo las circunstancias jurídicas descritas, nos encontramos frente a una discrecionalidad reglamentaria del Ejecutivo, la cual se puede predicar tanto en la expedición del reglamento como en la concreción e intensidad de los asuntos a desarrollar. La discrecionalidad en la expedición del reglamento se materializa en la libertad que tiene el titular para determinar bajo los criterios de conveniencia y oportunidad la necesidad de ejercer la potestad reglamentaria, por lo menos es la lectura que se hace del artículo 189.11, cuando expresa que le corresponde al presidente expedir reglamentos: “(...) necesarios para la cumplida ejecución de las leyes".

Bajo esta concepción de la discrecionalidad reglamentaria, resulta claro que el Ejecutivo se ha escudado tras el ejercicio de dicha libertad por casi cincuenta años para enfrentar el tema, con lo cual vulnera los derechos de los Conjueces a percibir una remuneración acorde al cargo que desempeñan, tal y como lo dispone la Ley 270 de 1996 EAJ.

Esta situación fue advertida a dentro del Salvamento de voto presentado en la Sentencia de la Corte Constitucional T-247 de $2003^{5}$, donde el magistrado

5 En esta sentencia un conjuez, solicita que se le tutele "la protección de su dignidad y de sus derechos a la igualdad y al trabajo, porque la Sala Administrativa del Consejo de la Judicatura pretende reconocerle, por los servicios prestados a la administración de justicia, como Conjuez de la Sala Laboral del Tribunal Superior de Medellín, una remuneración que no corresponde a la dignidad y a la responsabilidad del cargo" (Corte Constitucional, Sentencia T-247 de 2003) 
Montealegre Lynett expuso que debe admitirse que el derecho fundamental al mantenimiento del poder adquisitivo del salario se debe predicar también a la vinculación que implique prestación de funciones públicas, en la medida en que se trata de una "necesidad intermitente de funcionarios públicos" (Corte Constitucional, salvamento de voto, Sentencia T-427 de 2003).

El salvamento, enfatiza, que la actividad del Conjuez no es una actividad $A d$ Honorem, puesto que demanda una importante inversión de tiempo y exige una alta responsabilidad profesional; en conclusión, para el magistrado disidente dicha conducta se traduce en un enriquecimiento sin causa a favor de la administración.

Finalmente, el salvamento de voto plantea que la falta de actualización de las tarifas que remunera el cargo de Conjuez, puede generar un estado de cosas que resulta abiertamente inconstitucional, pues se trata de una conducta omisiva que ha permanecido por décadas y que ha generado un estado de cosas que resulta violatorio de la Constitución Política, a todos los abogados que han actuado como como Conjueces:

En el presente caso se observa que la administración ha incumplido la obligación establecida en el Decreto 1265 de 1970 de reajustar cada dos años la (sic) tarifas de los Conjueces. Como se analizó antes, ello ha conducido al reconocimiento de honorarios simbólicos a favor de personas que tienen un vínculo laboral especial con el Estado, desconociendo sus derechos constitucionales. (Corte Constitucional,2003. Salvamento de voto de Sentencia T-427 p. 21)

Diez años después de la decisión en comento, se evidencia un avance interesante en el tema, pues en el año 2018 se identifica en la página del Ministerio de Justicia, un proyecto de decreto publicado 17 de julio, por medio del cual "se actualizan los honorarios de los conjueces de la Rama Judicial" (Ministerio de Justicia, 2018), el cual estuvo colgado en la página web del ministerio para la recepción de opiniones y observaciones, desde el 17 de hasta el 22 de julio de 2018. Como soporte técnico para la expedición del proyecto de decreto, acude a un concepto emitido por la Sala de Consulta y Servicio Civil de 9 de noviembre de 2016, donde se conceptúa acerca de la naturaleza jurídica de la figura del Conjuez, la vigencia de las normas aplicables y el requerimiento los recursos para el rubro específico, "pago de honorario de conjueces" (Ministerio de Justicia, 2018) en el Presupuesto

En la sentencia solo se concede "el amparo constitucional al derecho de petición, y niega por improcedente, la protección a la remuneración vital y móvil”, en ese orden de ideas ordena a "la Sala Administrativa del Consejo Superior de la Judicatura que en las 48 horas siguientes a la notificación de esta decisión, defina la actuación iniciada por el demandante en febrero del 2001, con miras a obtener una remuneración vital y móvil, de conformidad al aparte 3.1. de esta decisión". 
General de la Nación. La norma se proyecta bajo la Dirección del entonces ministro de justicia Enrique Gil Botero, pero todavía no ha sido expedida por el Ejecutivo.

$\mathrm{Al}$ analizar el contenido de la propuesta normativa, resulta extraño que solo se fijen tarifas para los Conjueces que actúen ante la Altas Cortes y los Tribunales Superiores de distrito judicial y nada se diga respecto de los jueces ad-hoc.

\section{Inconsistencia sistémica de la normatividad vigente}

Para describir la normatividad vigente que rige a los Conjueces, es importante señalar que dicha institución no se encuentra prevista de manera expresa en la Constitución Política, pero sí de manera tácita en el artículo 116 cuando se refiere a que "los particulares pueden ser investidos transitoriamente de la función de administrar justicia". La ley Estatutaria de Administración de Justicia (en adelante LEAJ 270) (Congreso de la República, 1996) desarrolla la institución en el artículo 61 cuyo contenido retoma lo expresado en las normas anteriores a la Constitución de 1991, así como los requisitos, deberes y responsabilidades. De la norma se destaca especialmente: i) la prohibición de que los Conjueces hagan parte de las corporaciones públicas o ii) que se desempeñen como empleados o trabajadores de alguna entidad o iii) que cumpla funciones públicas durante el período de sus funciones.

Por su parte el Acuerdo 209 de 1997, reglamento expedido por el Consejo Superior de la Judicatura, en ejercicio de las competencias constitucionales establecidas en el artículo 257 numeral 30, establece las particularidades que se deben observar para la elección, sorteo, así como el funcionamiento y las responsabilidades de los Conjueces en todas las jurisdicciones ${ }^{6}$.

Desde la norma contencioso-administrativa, los artículos 115 y 116 de la Ley 1437 de 2011, reiteran lo descrito en la Ley 270 de 1996 (EAJ) respecto de la elección, posesión y duración del cargo de Conjuez, precisa la distinción entre los Conjueces externos y los Conjueces que ya son jueces; y autoriza que los magistra-

“Artículo 30. PROCESOS DE ELECCIÓN Y SORTEO. POSESIÓN. La sala plena, en el mes de diciembre de cada año, formará la lista de Conjueces en número doble al de los magistrados que integran la corporación, los cuales actuarán cuando se disminuya la pluralidad mínima prevista en el artículo 54 de la Ley 270 de 1996 o para dirimir los empates que se presenten en las salas en materia de decisión jurisdiccional. Esta lista estará integrada por abogados vecinos del lugar, que reúnan los requisitos para ser magistrados de la respectiva corporación.

Los servidores públicos no podrán ser designados Conjueces.

El sorteo de Conjueces se hará públicamente en la secretaría.

El presidente de la sala o sección en que el conjuez deba actuar fijará fecha y hora para tal acto. El conjuez que resulte sorteado tomará posesión ante el presidente de la sala o sección, dentro de los cinco días siguientes a aquél en que se le comunique la designación, y si no lo hiciere será reemplazado.

Cuando por cualquier causa se agote la lista de Conjueces, la sala o sección nombrará los que se requieran para el negocio. 
dos de la Sala de lo Contencioso Administrativo y de la Sala de Consulta y servicio Civil, bajo la figura del Conjuez, puedan moverse de una sala a otra:

Artículo 115: CONJUECES. Los Conjueces suplirán las faltas de los Magistrados por impedimento o recusación, dirimirán los empates que se presenten en la Sala Plena de lo Contencioso Administrativo, en la Sala de lo Contencioso Administrativo en sus diferentes secciones y en Sala de Consulta y Servicio Civil, e intervendrán en las mismas para completar la mayoría decisoria, cuando esta no se hubiere logrado.

Serán designados Conjueces, por sorteo y según determine el reglamento de la corporación, los Magistrados de las Salas de lo Contencioso Administrativo y de Consulta y Servicio Civil de la Corporación.

Cuando por cualquier causa no fuere posible designar a los Magistrados de la Corporación, se nombrarán como Conjueces, de acuerdo con las leyes procesales y el reglamento interno, a las personas que reúnan los requisitos y calidades para desempeñar los cargos de Magistrado en propiedad, sin que obste el haber llegado a la edad de retiro forzoso, las cuales en todo caso no podrán ser miembros de las corporaciones públicas, empleados o trabajadores de ninguna entidad que cumpla funciones públicas, durante el período de sus funciones. Sus servicios serán remunerados.

Artículo 116: POSESIÓN Y DURACIÓN DEL CARGO DE CONJUEZ. Designado el Conjuez, deberá tomar posesión del cargo ante el Presidente de la sala o sección respectiva, por una sola vez, y cuando fuere sorteado bastará la simple comunicación para que asuma sus funciones.

Cuando los Magistrados sean designados Conjueces sólo se requerirá la comunicación para que asuman su función de integrar la respectiva sala. (Congreso de la República, 2011, Ley 1437, subrayado propio)

De la norma en cita, salta a la vista la vulneración a las disposiciones constitucionales que establecen la necesaria independencia orgánica del Consejo de Estado en sus salas y secciones especializadas (artículos 236 y 237), respecto del ejercicio de la función jurisdiccional y consultiva, ya que autoriza que magistrados de la Sala de lo Contencioso Administrativo, así como de la Sala de Consulta y Servicio Civil, sean designados como Conjueces en dicha Corporación y "en cualquiera de las especialidades que la ley se ha encargado de separar".

También resulta controversial, que a pesar de que el artículo 61 de la Ley 270 de 1996, establezca que no podrían ser designados como Conjueces los "miembros de las corporaciones públicas, empleados o trabajadores de ninguna entidad que cumplan funciones públicas durante el período de sus funciones", la Ley 1437 admita que puedan ser nombrados como Conjueces a los que ya son jueces, lo que desnaturaliza la figura de Conjuez, entendida 
esta como terceros, es decir, como un juez externo a la corporación, de ahí la prohibición establecida.

Esta discusión fue advertida en una demanda de inconstitucionalidad, que fue resuelta mediante la Sentencia C-688 de 2017, donde desafortunadamente la Corte se declaró inhibida por considerar que la argumentación estructurada por la demandante carecía de especificidad, sin embargo en el salvamento de voto presentado por el magistrado José Fernando Reyes, echó de menos que la Corte conociera de fondo las pretensiones de la demanda de nulidad por inconstitucionalidad, expresando en tal sentido que:

(..) La Corte ha perdido una valiosa oportunidad para establecer si la delimitación para la designación de Conjueces en el Consejo de Estado en sus propios magistrados podría comprometer la independencia e imparcialidad judicial que debe caracterizar la administración de justicia ${ }^{7}$. No puede negarse la inquietud constitucional que genera el que las normas demandadas de la Ley 1437 de 2011, en una posible contradictio in terminis, permitan que los mismos consejeros de Estado actúen como Conjueces de sus pares, que obran como los jueces competentes en el caso específico, en las decisiones proyectadas por sus colegas, lo cual podría comprometer los aludidos atributos que justamente se exigen de aquellos.

Así, de haberse abordado el estudio material de las normas demandadas, la Corte hubiera podido aclarar la aparente falta de coherencia sistémica de sus previsiones, ya que estas erigen en Conjuez a quien ya es juez. Al respecto no debe perderse de vista que, si la vocación de un Conjuez en múltiples ocasiones es, por ejemplo, dirimir un empate entre posturas que se evidencian antagónicas, esto es, un tercero ajeno a la Corporación, garantizaría que no haya solidaridades científicas fundadas en razones diferentes a la coherencia argumentativa. En ese orden, de cara a la pertinencia necesaria que reclama un cargo que pretende atacar una norma por inconstitucional, en este evento la censura por puesta en duda del principio del debido proceso (Corte Constitucional, 2006, Sentencia T-080, reiterada en auto 169 de 2009.), en su faceta de la imparcialidad y la independencia ${ }^{8}$ no se

7 La independencia e imparcialidad judicial que se reclama de los jueces demanda la ausencia total de factores internos o externos que puedan alterar su objetividad. Un factor interno podría ser la tendencia de los magistrados de una corporación a estar de acuerdo con la posición de uno o varios de sus colegas (corporativismo), obviando lo que objetivamente pueda ser más justo en un caso determinado.

8 Esta Corte ha explicado la diferencia entre los atributos de imparcialidad e independencia, señalando que: "[la] independencia, como su nombre lo indica, hace alusión a que los funcionarios encargados de administrar justicia no se vean sometidos a presiones, [...] a insinuaciones, recomendaciones, exigencias, determinaciones o consejos por parte de otros órganos del poder, inclusive de la misma rama judicial, sin perjuicio del ejercicio legítimo por parte de otras autoridades judiciales de sus competencias constitucionales y legales". Sobre la imparcialidad, ha considerado que esta "se predica del derecho de igualdad de todas las personas ante la ley (Art. 13 C.P.), garantía de 
antoja imposible, o lejano o en todo caso carente de toda posibilidad de ser discutido. (Corte Constitucional, 2017.Sentencia C-688)

Y es que la preocupación que expresa el magistrado José Fernando Reyes no resulta solitaria, se suma a una preocupación que el Ejecutivo dejó ver con la expedición del Decreto 2697 de 2004, por medio del cual intentó reformar el artículo $61 \mathrm{LEAJ}^{9}$, al establecer que los conflictos judiciales donde actúen como partes o terceros intervinientes funcionarios o empelados de la Rama Judicial, debían resolverse por unas las salas de Conjueces especiales muy distintas a las tradicionales. Para la conformación de dichas salas, la norma suspendida propuso desplazar la competencia que tradicionalmente se le había entregado a las Sala Plena del Consejo de Estado y a los Tribunales Administrativos, para entregársela al Procurador Judicial, al Contralor General de la República, de la siguiente manera:

(...) Parágrafo. Los procesos judiciales que deban conocer las corporaciones judiciales en donde actúen como partes o terceros intervinientes funcionarios o empleados de la Rama Judicial, serán siempre dirimidos por salas de Conjueces adscritas a las respectivas corporaciones integradas de la siguiente manera: Un Conjuez designado por el Procurador General de la Nación; un Conjuez designado por el Contralor General de la República; un tercer Conjuez que será designado de común acuerdo por los dos Conjueces designados en la forma descrita. Estos Conjueces deberán reunir las mismas condiciones que para ser magistrado de la respectiva corporación y estarán sometidos al mismo régimen de inhabilidades e incompatibilidades previsto para los funcionarios judiciales. (Ministerio de justicia, 2004)

Se trató de una propuesta normativa, que partió de reconocer una afectación de la independencia judicial del Conjuez que va a resolver los conflictos jurídicos que involucran los intereses de la Rama Judicial y en el cual pueden tener especial interés los jueces encargados de nombrarlos.

Finalmente, en lo concerniente al régimen de impedimentos y recusaciones descritos en los artículos 130 de la Ley 1437 de 2011 y el artículo 141 de la Ley 1564 de 2012, surgió una discusión relacionada con una aparente omisión legislativa relativa, según la cual ni la norma procesal civil ni el contencioso ad-

la cual deben gozar todos los ciudadanos frente a quien administra justicia. Se trata de un asunto no sólo de índole moral y ética, en el que la honestidad y la honorabilidad del juez son presupuestos necesarios para que la sociedad confíe en los encargados de definir la responsabilidad de las personas y la vigencia de sus derechos, sino también de responsabilidad judicial" (negrilla fuera del texto original) (Corte Constitucional, Sentencia C-365 de 2000).

9 Adicionado por el Artículo 9 del Decreto Nacional 2697 de 2004 “Por el cual se corrigen yerros tipográficos del Decreto 2637 del 19 de agosto de 2004 por el cual se desarrolla el Acto Legislativo número 03 de 2002" SUSPENDIDO provisionalmente por el Consejo de Estado. 
ministrativo consagra prohibición alguna para que una persona que actúa como Conjuez juzgue a quien ha sido actualmente su contraparte en otro proceso.

Esta discusión fue planteada a partir de una demanda de inconstitucionalidad resuelta con la Sentencia C-496 de 2016, debido a una aparente omisión legislativa relativa, pues la norma vigente no contempla la causal: "haber sido o ser contraparte de alguna de las partes o sus apoderados". Dicho planteamiento resulta absolutamente válido, pues se trata de un régimen diseñado a la medida de los jueces vinculados de manera permanente a la Rama Judicial, desconociendo la diferencia estructural del ejercicio profesional entre el abogado que solo es juez y el que ejerce como juez esporádicamente, pero dedica su actividad profesional a ejercer la abogacía, es decir el litigio.

El demandante explicó que cuando el legislador “jamás contempló la posibilidad de que dicho juez se enfrentara como contraparte a una de las partes en sus propios procesos, en vista de que [a] los jueces les está vedado el ejercicio profesional de la abogacía" (Corte Constitucional, 2013, Sentencia C-222), bajo lo expuesto, pese a que la falta de regulación de la causal de impedimento para los Conjueces vulnera derechos fundamentales, como el acceso a la administración de justicia, la igualdad y el debido proceso, la Corte decidió declarar exequible los artículos demandados, por encontrar infundados los cargos ${ }^{10}$.

Del recuento normativo, se puede observar que la regulación de la institución de los Conjueces da claridad en lo que tiene que ver con su responsabilidad disciplinaria y penal, régimen de inhabilidades e incompatibilidades, así lo reiteró la Ley 734 de $2002^{11}$ cuando prescribió el artículo 217 "el régimen disciplinario para los Conjueces en la Rama Judicial comprende el catálogo de deberes y prohibiciones previstas en la Ley Estatutaria de la Administración de Justicia” condicionando dicha aplicación a una evaluación de compatibilidad con el caso en que deban actuar; la misma norma también establece la aplicabilidad del régimen de inhabilidades e incompatibilidades, impedimentos y conflictos de intereses, el catálogo de faltas gravísimas (art. 2018), competencia para su juzgamiento (art. 216), y graduación de las sanciones (art. 219) que no se detiene a analizar las particularidades que tienen el Conjuez en su ejercicio.

10 En uno de los argumentos de la sentencia se explicó que: "en los procesos regulados por cada una de esas codificaciones, si bien no basta con acreditar el hecho objetivo de que el juez o conjuez sea o haya sido contraparte de las partes o de sus apoderados, este elemento puede articularse con otros para contribuir a demostrar la concurrencia de una causal de recusación o impedimento, como por ejemplo al aducir enemistad grave, amistad íntima, interés moral, o haber sido parte en el mismo proceso o denunciante en un proceso penal o disciplinario anterior o concomitante. A todo lo cuales ha de sumarse que además de estas hay otras hipótesis de recusación e impedimento, contenidas en las normas legales cuestionadas, y que en conjunto ofrecen instrumentos suficientes de imparcialidad para todas las personas" 
La normatividad revisada no da cuenta de una noción de Conjuez, ni de su la naturaleza jurídica; no hay claridad acerca de su régimen jurídico pues la remisión normativa que se hace no permite aclarar si es titular todos o algunos de los derechos descritos en el artículo 152 de la Ley 270 de 1996 (LEAJ) (participar en programas de capacitación, percibir una remuneración acorde con su función, dignidad y jerarquía que no puede ser disminuida de manera alguna, a la protección y seguridad física y la de sus familiares, por ejemplo); y en el mismo sentido si los deberes y prohibiciones que contemplan los artículos 153 y 154 le son exigibles (a efectos penales y disciplinarios), e incluso si se puede hacer acreedor de los estímulos y distinciones que le son aplicables al funcionario judicial que ostenta la relación legal y reglamentaria, entre otros aspectos. En todo caso, las respuestas a estas cuestiones están subordinadas a que se pueda esclarecer la noción y naturaleza jurídica de la institución del Conjuez en Colombia, así como el alcance que tiene.

\section{La naturaleza jurídica del conjuez en Colombia ¿Particulares que administran justicia transitoriamente? ¿Funcionarios sui generis?}

La administración de justicia es una función pública esencial (arts. 228 de la Constitución de 1991 y 125 de la Ley 270 de 1996 LEAJ), a través de ella se buscan preservar los valores y garantías contenidos en la constitución (Corte Constitucional 2006, Sentencia C-323). Para cumplir los fines mencionados, el Estado designó la función de administrar justicia en servidores públicos (magistrados, jueces, consejeros de Estado) y en particulares a quienes se les atribuye transitoriamente funciones jurisdiccionales (Congreso de la República, 1996. Artículo 116, 246, 247 del C.P. y arts. 12 y 13 de la Ley 270 LEAJ).

De la lectura del artículo 116 de la Constitución Política, es posible observar que la autorización que se otorga a los particulares revestidos transitoriamente de la función pública de administrar justicia, se confiere, en principio, a los jurados en las causas criminales, conciliadores o en la de árbitros habilitados por las partes, para proferir fallos en derecho o en equidad. Por su parte, el artículo 247 de la Constitución crea la institución del juez de paz (desarrollado por la ley 497 de 1999) a quien le atribuye también el ejercicio de competencias jurisdiccionales, y en el mismo sentido, el artículo 246, reconoce la competencia de los pueblos indígenas.

El citado artículo 116 de la Constitución Política, no enumera restrictivamente los eventos en que los particulares pueden ejercer funciones jurisdiccionales (Corte Constitucional,2005, Sentencia C-059; Corte Constitucional, 1995, Sentencia C-536), por lo que otras normas del ordenamiento jurídico (Constitucion o ley) 
pueden revestir de competencia a particulares para que ejerzan funciones jurisdiccionales, la Ley 270 EAJ lo desarrolla así en los artículos 12 y 13.

Sobre el tema existe una tratamiento incipiente por parte de la doctrina, pues solo es posible identificar un trabajo académico que se ocupó del tema el cual se trazó como propósito brindar "Un panorama sobre la figura del Conjuez como administrador de justicia en el sistema jurídico colombiano" (Salazar Olivella, 2015); de esta manera la autora advierte las diferentes posiciones que suscita la discusión acerca de su naturaleza jurídica: la primera, que son empleados públicos, la segunda que se trata de particulares que ejercen la función pública de administrar justicia; y la tercera, que se trata de servidores públicos que tienen un vínculo de prestación de funciones públicas con el Estado. En el trabajo de investigación, para la autora Salazar Olivella, se trata de un particular que administra justicia.

Por su parte, de la revisión de la jurisprudencia de la Corte Constitucional y del Consejo de Estado, se advierten también tres miradas acerca de la naturaleza de la figura: i) Es un tercero que administra justicia; ii) es un servidor público que administra justicia, sujeto a un régimen especial; iii) son servidores públicos transitorios

\section{Consejo de Estado: Es un tercero que administra justicia}

Respecto de las posiciones expuestas, la sección quinta del Consejo de Estado toma partido en la sentencia proferida el 24 de junio de 2010, cuando intentó definir no solo la naturaleza jurídica de la institución del Conjuez, sino también la noción de Conjuez en los siguientes términos:

La institución del Conjuez, que se define como "Juez juntamente con otro en un mismo negocio", figura tácitamente consagrada en el artículo 116 de la Constitución, modificado por el artículo $1^{\text {o }}$ del Acto Legislativo 03 de 2002, al decir que "Los particulares pueden ser investidos transitoriamente de la función de administrar justicia.... Corresponde a una de las formas permitidas por el constituyente para que los particulares se vinculen, de manera temporal o para un negocio respectivo, a la función de administrar justicia, ya que dichos colaboradores de la administración de justicia entran a actuar, regularmente, en cuerpos colegiados cuando alguno de los magistrados titulares no puede hacerlo por el deber que tiene de separarse del conocimiento de un asunto, cuando se ha declarado impedido o cuando frente a él ha prosperado una recusación, e igualmente se necesita su presencia cuando por las circunstancias de la votación respectiva ninguna de las posiciones sometidas a consideración obtiene la mayoría requerida (...). (Consejo de Estado, 2010, Sentencia 2009-00051) 
Esta definición, pareciera no comprender los jueces que han denominado $a d d o c$, pero resulta lógico por estar invisibilizados en el ordenamiento jurídico.

Corte Constitucional: es un servidor público que administra justicia, sujeto a un régimen especial

La postura asumida por la sentencia de la Corte Constitucional en la Sentencia C-037 de 1996, explica que su naturaleza es la de servidor público cuando actúa en cada caso concreto que atiende, pero que por sus particularidades se trata de un servidor sui generis, es decir que su condición es muy singular, y que no puede confundirse con aquellos particulares investidos transitoriamente de la función de administrar justicia, como ocurre con los árbitros y jueces de paz; dicha argumentación no es clara, dado que no permita explicar el alcance jurídico de tal condición, por ejemplo, como se advirtió en párrafos precedentes, ¿dicha condición le permitiría a los Conjueces exigir los derechos que enumera la Ley 270 LEAJ, propios de los funcionarios judiciales, en carrera o en provisionalidad que ostentan una relación legal y reglamentaria? ¿Qué es lo suis generis? ¿Qué los diferencia de un Juez de Paz y un árbitro?

Esta perspectiva de análisis fue controvertida en el salvamento de voto realizado por el magistrado Vladimiro Naranjo, en la Sentencia 037 de 1996, al considerar que los Conjueces en realidad ostentan la calidad de particulares y que de manera transitoria cumplen funciones jurisdiccionales. Explicó el magistrado que los Conjueces no pueden revestir la calidad de servidores públicos porque, ni son miembros de corporaciones públicas, ni empleados, ni trabajadores del Estado y advierte las dificultades que surgen al otorgarle la naturaleza jurídica de servidores públicos:

Que una corporación judicial elija una lista de Conjueces, no significa que ellos, por ese simple hecho, sean servidores públicos, pues de ser ello así, entonces debería aplicárseles igualmente todo el régimen previsto en la Constitución para estos funcionarios, lo cual constituye un despropósito de tal magnitud que no resiste ninguna consideración jurídica y menos una de orden constitucional. Por tales motivos, debe aceptarse que los Conjueces fuesen en realidad particulares que desempeñan transitoriamente funciones públicas. (Corte Constitucional,1996, salvamento de voto de Sentencia C-037)

En una sentencia posterior, el magistrado Eduardo Montealegre, de nuevo advirtió que no es claro el estatus jurídico del Conjuez, en relación con su vínculo con el Estado, descarta la existencia de un vínculo de naturaleza laboral, pues "los Conjueces únicamente ejercen funciones públicas de manera temporal, cuando los jueces o magistrados se encuentran imposibilitados para ejercer la función. No 
se presentan, por lo tanto, las condiciones básicas de la una relación de carácter laboral" (Corte Constitucional, 2003. Salvamento de voto, Sentencia T-427).

\section{La Sala de Consulta y Servicio Civil: son servidores públicos transitorios}

Interviene también en esta discusión, un concepto emitido por la Sala de Consulta y Servicios Civil que, adoptando la postura de la Corte Constitucional, se refiere a al carácter transitorio de los mismos, sus deberes y responsabilidades, y al deber de remuneración de su actividad, así conceptuó:

Los Conjueces son servidores públicos transitorios sujetos a un régimen especial. Ejercen transitoriamente función judicial, asumen las atribuciones propias de los jueces y quedan sujetos a su mismo régimen de responsabilidades, deberes, impedimentos y recusaciones. Según los artículos 61 de la Ley Estatutaria de Administración de Justicia y 115 de la Ley 1437 de 2011, sus servicios serán remunerados. ( Sala de Consulta y Servicios Civil, 2016, Concepto 2303)

La Sala se refiere al carácter transitorio de la actividad del Conjuez, pero lo sigue enmarcando dentro del carácter de servidor público de régimen especial, pero ¿Dónde está contemplado dicho régimen?; se preocupa por aclarar que no existe una relación jurídica subjetiva de carácter laboral y que "el ejercicio transitorio de función judicial por parte de los Conjueces los ubica en una categoría diferente a la de los 'auxiliares de la justicia'” (Sala de Consulta y Servicios Civil, 2016, Concepto 2303,).

De lo descrito, es claro que los Conjueces cuando se desempeñan en los distintos procesos donde son llamados, lo hacen sin que haya claridad en torno al tipo de relación jurídica que surge, pero con la certeza de que se les aplica el mismo régimen de deberes, atribuciones y responsabilidades de cualquier servidor púbico en cargado de administrar justicia, tal y como lo anuncia, por ejemplo, la Ley 1437 de 2011 en el artículo 115: "Los Conjueces tienen los mismos deberes y atribuciones que los magistrados y estarán sujetos a las mismas responsabilidades de estos" (Congreso de la República, 2011, Ley 1437), por su parte el artículo 61 de la Ley 270 de 1996 LEAJ, cuando establece que: "Los Conjueces tienen los mismos deberes que los magistrados y estarán sujetos a las mismas responsabilidades de éstos" (Congreso de la República, 1996, Ley 270).

Bajo el régimen jurídico actual el Conjuez goza de una remuneración por honorarios, la cual solo se activa por una reclamación directa ante la administración judicial, lo que resulta contrario al deber que tiene el Estado de remunerar la actividad, especialmente, se ha evidenciado que dicho trámite expone al reclamante a un viacrucis jurídico, como el descrito en la Sentencia T-247 de 2003, donde la misma la Corte Constitucional toma una postura evasiva frente al tema. 
Aunque en lo descrito en la jurisprudencia no se presenta un panorama claro acerca de la naturaleza jurídica del Conjuez, tomamos la postura según la cual los Conjueces son particulares que ejercen la función pública de administrar justicia, similar a como sucede con los árbitros, por tres razones: 1) Ejercen su actividad de forma transitoria, pues no se reúnen los elementos para que se configure una relación laboral, de carácter legal y reglamentaria; 2) los terceros que son nombrados Conjueces ejercen su actividad profesional libremente, lo que no impide que puedan ejercer de manera concomitante la función pública de administrar justicia, situación que incluso obliga a pensar que esta implica que necesariamente se cree un régimen especial de inhabilidades e incompatibilidades que observe tal particularidad que puede afectar su imparcialidad y neutralidad; y 3) la denominación "servidor público con régimen especial", no está contemplado dentro del ordenamiento jurídico colombiano, es decir, no existe un régimen legal especial que cobije y desarrolle el alcance y condiciones de la figura del Conjuez.

\section{Consideraciones en torno la implementación de la figura del conjuez, en la jurisdicción contencioso administrativa}

En la jurisdicción contencioso administrativa, existe un volumen considerable de demandas de funcionarios de la Rama Judicial, que ha generado un reiterado llamado a los Conjueces y jueces ad hoc. Como ya se mencionó, en su gran mayoría, se trata de asuntos de carácter laboral, donde generalmente están comprometidos intereses de funcionarios judiciales. Lo que conlleva a la declaratoria masiva de impedimentos para conocer de los procesos, por tener un interés directo o indirecto en el resultado del litigio. Como consecuencia de ello, surge la necesidad de reconformar en su totalidad la sala de decisión (o en el caso de los juzgados administrativos, nombrar un juez ad hoc), haciendo uso de las listas de abogados externos que se postularon y que fueron nombrados como Conjueces ante dicha jurisdicción.

A partir de la información recopilada entre el segundo semestre del año 2017 y el primero del 2018, proveniente de las relatorías de trece (13) de los veintiséis (26) Tribunales Administrativos y de las cinco secciones del Consejo de Estado, fue posible observar el siguiente panorama por cada Tribunal:

En el Gráfico 1 es posible identificar que están en curso un número considerable de procesos, que demandan la participación permanente de Conjueces en los distintos en los Tribunales Administrativos, siendo los de Cundinamarca, Caldas, Boyacá y Antioquia, los que el mayor número de procesos activos muestra.

Con relación a los Conjueces activos, los Tribunales de Cundinamarca, Caldas y Boyacá, son los que reflejan una relación mayor de procesos vs. número de 
La institución del Conjuez en Colombia...

Gráfico 1. Estadística Conjueces en la JCA/Tribunales

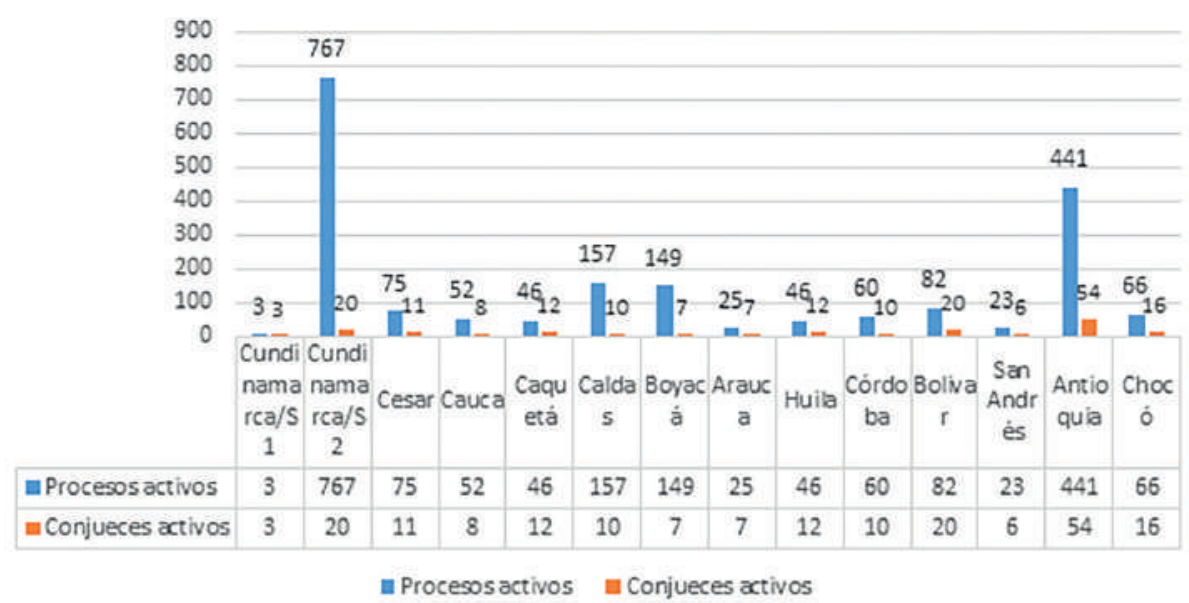

Fuente: creación propia.

Gráfico 2. Promedio de procesos por Conjuez/Tribunales

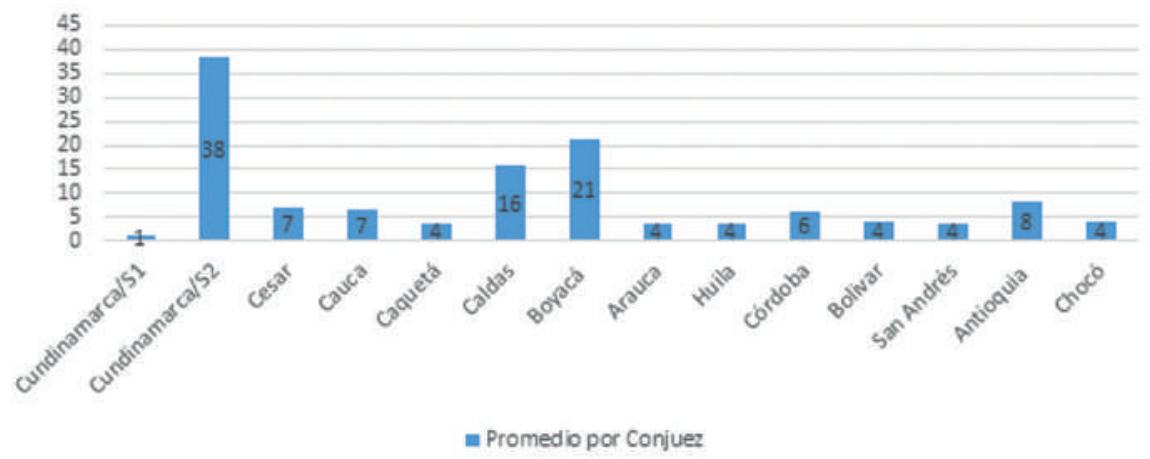

Fuente: creación propia

Conjueces, siendo 38 el número de casos asignados más alto y 1 el más bajo. Por su parte, en la Tabla 1 se observa que las cifras que evidencia la estadística del Consejo de Estado muestra detalladamente de la relación procesos activos/Conjueces activos/y promedio de casos por conjuez, lo que da cuenta de la existencia un número importante de asuntos a cargo de Conjueces: 
Tabla 1. Estadística Conjueces Consejo de Estado

\begin{tabular}{cccc}
\hline Sección & Conjueces activos & Procesos activos & Promedio por Conjuez \\
\hline 1 & 8 & 330 & 41 \\
2 & 12 & 293 & 24 \\
3 & 18 & 0 & 0 \\
4 & 5 & 50 & 10 \\
5 & 7 & 19 & 2 \\
\hline
\end{tabular}

Fuente: creación propia

Desde una perspectiva más global, el Gráfico 3, describe la distribución de los seiscientos noventa y dos procesos (692) procesos en curso en las cinco (5) secciones, a cargo de los Conjueces, donde se destaca que la sección tercera no tenía procesos a cargo de Conjueces (0 \%) y la sección primera es la que mayor número de casos activos presenta con el cuarenta y ocho por ciento (48\%) de asuntos a su cargo.

Gráfico 3. Relación total vs. Procesos por secciones del C.E.

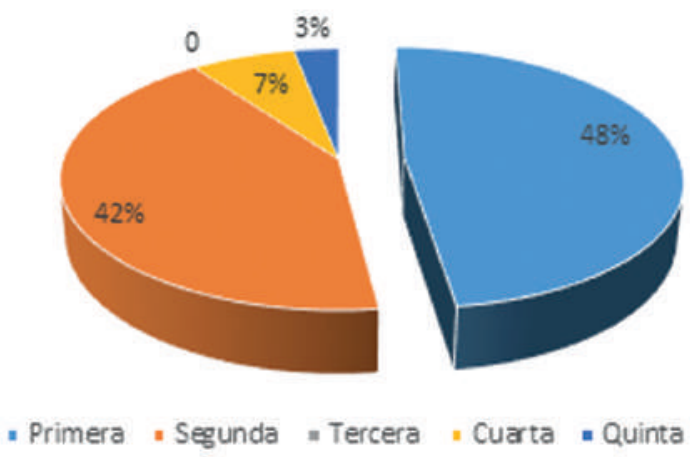

Fuente: creación propia

Como último hallazgo de la investigación, fue posible observar en el caso de los jueces ad hoc, que venían asumiendo el conocimiento sobre las reclamaciones salariales y prestacionales de la Rama Judicial, se identificó una situación apremiante de congestión juridicial que llevó a tomar medidas administrativas, mediante el Acuerdo PCSJA19-11331 de 2019. Dicha medida consistió en crear despachos judiciales en cabeza de Jueces Administrativos exclusivos y especiales para atender dichos asuntos: 
Artículo $2^{\circ}$. Crear con carácter transitorio a partir de 8 de julio y hasta el 13 de diciembre de 2019: a. Dos (2) juzgados administrativos en Bogotá conformados por un juez, un sustanciador y un profesional universitario grado 16. b. Un juzgado administrativo en Medellín conformado por un juez, un sustanciador y un profesional universitario grado 16. c. Un juzgado administrativo en Yopal conformado por un juez y un sustanciador.

PARÁGRAFO PRIMERO. Los juzgados administrativos de Bogotá y Medellín tendrán a cargo los procesos sobre las reclamaciones salariales y prestacionales de la Rama Judicial.

El nominador velará porque las personas designadas como servidores judiciales no tengan ningún impedimento para conocer de los procesos que le sean asignados. (Consejo Superior de Judicatura, 2019, Acuerdo PCSJA19-11331, Negrilla propia)

Dicha medida, demuestra que si es posible tomar medidas administrativas para garantizar el derecho al acceso a la administración de justicia de los demandantes interesados en las reclamaciones salariales y prestacionales de la Rama Judicial, lo mismo se podrá hacer con relación a los Conjueces, que en estos mismos asuntos, cumplen sus funciones de manera precaria y desventajosa.

\section{Conclusiones}

Las normas procesales autorizan que los integrantes de la Sala Plena del Consejo de Estado y Tribunales de distrito judicial puedan nombrar Conjueces en causas donde ellos se han declarado impedidos, particularmente en los casos que tratan el reconocimiento de derechos laborales en disputa. Lo anterior puede comprometer el derecho al debido proceso desde sus facetas de la independencia judicial y la imparcialidad.

El tratamiento que ha dado la jurisprudencia, la Corte Constitucional y del Consejo de Estado, acerca de la determinación de su naturaleza jurídica no es clara, pues se cataloga como un servidor público sui generis, sin precisar claramente a qué se refiere cuando le otorga dicha categoría y cuál es el régimen jurídico aplicable (si se trata de un particular que transitoriamente presta un servicio público o si es un servidor público); bajo el régimen actual solo lo hace titular de deberes, vigilados de manera estricta desde la esfera penal y disciplinaria; y de manera incipiente y dispersa el reconocimiento de derechos.

La ausencia de remuneración por los servicios que presta el Conjuez a la administración de justicia, está relacionada con la falta de interés por parte del Ejecutivo de actualizar las tarifas establecidas mediante el Decreto Extraordinario 
2204 de 1969, pues la misma norma señaló que la remuneración de los servicios de los Conjueces debía fijarse bianualmente por el Gobierno Nacional; se trata de una facultad discrecional del ejercicio de la potestad reglamentaria y que, a pesar de que lesione derechos fundamentales, tal parece que el Ejecutivo se puede resguardar en dicha potestad.

Existe un cúmulo importante de procesos en curso a cargo de los Conjueces en el Consejo Estado (Secciones primera, segunda y cuarta) y en los Tribunales Administrativos de Antioquia, Cundinamarca, Caldas, Boyacá y Atlántico, lo que requiere de medidas administrativas, similares a las tomadas en los casos de los procesos atendidos por los jueces ad hoc (creación de jueces transitorios), en tanto no se fortalezca al Conjuez que está al servicio de Tribunales y Consejo de Estado.

En la jurisdicción contencioso administrativa, y desde la perspectiva del derecho al debido proceso (en su arista de imparcialidad judicial), se establecen una serie de recomendaciones tendientes a: i) Reevaluar el sistema de selección de y nombramiento de los Conjueces, donde los funcionarios que los eligen, no tengan interés directo o indirecto en los asuntos que le van a ser encomendados (Caso de las demandas de Nulidad y Restablecimiento del Derecho Laboral en contra de la Rama Judicial para determinar el alcance de ciertos derechos y prestaciones); ii) se advierten importantes contradicciones entre los artículos 116 y 117 de la Ley 1437 de 2011, con el artículo 116 de la Ley 270 EAJ (la cual hace parte del bloque de constitucionalidad en sentido amplio) al convertir en Conjueces de la Sala contencioso Administrativa a los magistrados de la Sala de Consulta y Servicios Civil, y viceversa. Sumada a la prohibición nombrar Conjueces a los Servidores Públicos; y iii) existe una imperiosa necesidad de expedir un régimen jurídico que dé cuenta de las particularidades de la institución de Conjuez, que esclarezca su régimen de derechos y obligaciones, remuneración, relación de colaboración con los tribunales de distrito judicial y despachos; régimen de impedimentos y recusaciones especiales.

\section{Referencias}

Colombia. Consejo Superior de la Judicatura. Acuerdo PCSJA19-11331(2 de julio de 2019). Por el cual se crean medidas transitorias en el territorio nacional. Bogotá D.C., Colombia. Publicado el 13 de julio de 2019.

Colombia. Sala de Consulta y Servicios Civil. (9 de noviembre de 2016). Concepto 2303. Radicación n. - 11001-03-06-000-2016-00113-00(2303). Recuperado de https://www.procuraduria.gov.co/relatoria/media/file/flas_juridico/1643_CERad-2016-00113-00.pdf 
Colombia. Congreso de la República. (18 de enero de 2011). Ley 1437 de 2011. Por la cual se expide el Código de Procedimiento Administrativo y de lo Contencioso Administrativo. Diario Oficial n. 47.956 Bogotá D.C., Colombia.

Colombia. Congreso de la República. (18 de noviembre de 1910). Ley 81 de 1910. La cual se expide En desarrollo del artículo 85 del Acto Legislativo número 3 de 1910, reformatorio de la Constitución, y sobre procedimiento para el recurso de casación. Bogotá D.C., Colombia.Recuperado de http://www.suin-juriscol.gov.co/ viewDocument.asp?ruta=Leyes $/ 1626405$

Colombia. Congreso de la República. (15 de marzo de 1996), Ley 270. Estatutaria de Administración de Justicia. Diario Oficial n. 42.745 Bogotá D.C., Colombia. Recuperado de http://www.secretariasenado.gov.co/senado/basedoc/ ley_0734_2002_pr005.html\#216

Colombia. Consejo de Estado. (24 de junio de 2010). Sentencia 2009-00051. Radicación: 11001-03-28-000-2009-00051-00. Colombia. Recuperado de www. consejodeestado.gov.co

Colombia. Consejo de Estado. Sala de Consulta y Servicio Civil. Concepto 2303. (9 de noviembre de 2016). Radicación: 11001-03-06-000-2016-00113-00(2303). Consejero Álvaro Namén Vargas. Bogotá, Colombia. Recuperado de https://www. funcionpublica.gov.co/eva/gestornormativo/norma.php?i=79518

Colombia. Corte Constitucional. (17 de septiembre de 1993). Sentencia T-399, T-14223. Recuperado de http://www.corteconstitucional.gov.co/relatoria/1993/T-399-93.htm

Colombia.Corte Constitucional. (25 de noviembre de 1993). Sentencia C-544, D-284 Recuperado de http://www.corteconstitucional.gov.co/relatoria/1993/C-544-93.htm

Colombia.Corte Constitucional. (22 de septiembre de 1994), Sentencia C-416. Recuperado de http://www.corteconstitucional.gov.co/relatoria/1994/C-416-94.htm

Colombia.Corte Constitucional. (23 de noviembre de 1995). Sentencia C 536. Expediente D-950. Recuperado de http://www.alcaldiabogota.gov.co/sisjur/normas/ Norma1.jsp?i=4554

Colombia. Corte Constitucional. (5 de febrero de 1996). Sentencia C-037 de 1996, P.E.-008 Recuperado de http://www.corteconstitucional.gov.co/ relatoria/1996/C-037-96.htm

Colombia.Corte Constitucional. (5 de Febrero de 1996). Salvamento de Voto, Sentencia C-037 de 1996. Recuperado de http://www.corteconstitucional.gov.co/ relatoria/1996/C-037-96.htm

Colombia. Corte Constitucional. (21 de marzo de 2003). Salvamento de Voto, Sentencia T-427/03. Recuperado de http://www.corteconstitucional.gov.co/ relatoria/2003/T-247-03.htm\#_ftnref15

Colombia. Corte Constitucional. (16 de diciembre de 2004). Sentencia T-1249. Recuperado de http://www.corteconstitucional.gov.co/relatoria/2004/T-1249-04.htm 
Colombia. Corte Constitucional. (9 de febrero de 2006). Sentencia T-080

Colombia.Corte Constitucional. (1 de Febrero de 2005). Sentencia C-059. Referencia: expediente D-5244. Recuperado de http://www.corteconstitucional.gov.co/ relatoria/2005/c-059-05.htm

Colombia. Corte Constitucional. (24 de abril de 2006). Sentencia C-323. Referencia: expediente OP-121.

Colombia. Corte Constitucional. (17 de abril de 2013). Sentencia C -222, D-9317 (Corte Constitucional de Colombia 17 de Abril de 2013). Recuperado el 15 de noviembre de 2016 de http://www.corteconstitucional.gov.co/RELATORIA/2013/C-222-13. htm\#_ftnref 7

Colombia.Corte Constitucional. (15 de julio de 2015). Sentencia T-441 de 2015. Recuperado de http://www.corteconstitucional.gov.co/relatoria/2015/T-441-15.htm

Colombia.Corte Constitucional. (14 de septiembre de 2016). Sentencia C-496. Referencia: Expediente D-11258. Recuperado de http://www.corteconstitucional. gov.co/relatoria/2016/C-496-16.htm

Colombia.Corte Constitucional. (22 de noviembre de 2017). Sentencia C-688/17. Recuperado de

Colombia. Presidente de la República.(1969). Decreto 2204 de 1969. Por el cual se dictan normas relacionadas con los auxiliares y colaboradores de la justicia, práctica de diligencias, arancel y remuneración de Conjueces.

Colombia. Presidente de la República. (1984). Decreto 01 de 1984. Por el cual se reforma el Código Contencioso Administrativo.

De Zubiría Samper, A. (2012). La historia de la Rama Judicial en Colombia. Criterio Jurídico Garantista. (6), 154-187. Recuperado de http://www.fuac.edu.co/recursos_web/documentos/derecho/revista_criterio/articulosgarantista6/08_Historia_de_la_rama_judicial.pdf

Londoño Jaramillo, M. (2008). La congestión y la mora judicial: el juez, ¿Su único responsable? Revista Facultad de Derecho y Ciencias Políticas de la UPB, 38(109), 385-419. Recuperado de https://revistas.upb.edu.co/index.php/derecho/article/ view/669/613

Ministerio de Justicia. (31 de julio de 2018). Proyecto de decreto por el cual se actualizan los honorarios de los conjueces de la Rama Judicial. Recuperado de https:// www.minjusticia.gov.co/Portals/0/Proyectos_Decretos/Proyecto_Decreto_ actualizaci\%C3\%B3n_remuneraci\%C3\%B3n_conjueces_17072018.pdf

Ministerio de Justicia. (31 de julio de 2018). Soporte Tecnico decreto tarifas conjueces. Recuperado de https://www.minjusticia.gov.co/Portals/0/Proyectos_Decretos/Soporte_Tecnico_decreto_tarifas_conjueces.pdf

Ministerio de Justicia. (19 de agosto de 2004). Por el cual se desarrolla el Acto Legislativo número 03 de 2002. Recuperado de https://www.google.com/search?q=Decreto+2 
$637+$ de $+2004 \&$ oq $=$ Decreto $+2637+$ de $+2004 \&$ aqs $=$ chrome..69i57j012j69i60.667j0j8 \&sourceid $=$ chrome \&ie $=$ UTF- 8

Ministerio de Justicia. (2 de enero de 1984). Decreto 01 por el cual se expide el Codigo Contencioso Administrativo. Recuperado de http://www.alcaldiabogota.gov.co/sisjur/ normas/norma1.jsp?i=6543

Ministerio de Justicia. (28 de julio de 1970).Decreto 1265 Por el cual se expide el estatuto orgánico de la administración de justicia . Recuperado de http://www.suin-juriscol. gov.co/viewDocument.asp?id=1255158

Salamanca Charria, B. E. (2014). Anotaciones sobre la Historia del Derecho Procesal y la Administración de Justicia. Cali: Sello Editorial Javeriano.

Salazar Olivella, M. P. (2015). Regimen jurídico de los conjueces: naturaleza jurídica del vínculo con el estado y constitucionalidad de las normas sobre su remuneración. Bogotá, Colombia: Universidad Externado de Colombia. 